Volume 10, No.1, January - February 2021

International Journal of Advanced Trends in Computer Science and Engineering

Available Online at http://www.warse.org/IJATCSE/static/pdf/file/ijatcse401012021.pdf

https://doi.org/10.30534/ijatcse/2021/401012021

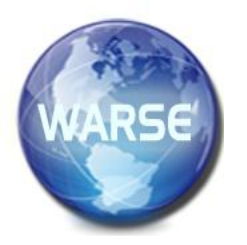

\title{
Smart Alarm Traffic Management System for the Major Road to Isolation Hospital during the Covid-19 Pandemic in Port Said City
}

\author{
Marwa Elbany ${ }^{1}$,Heba Soliman ${ }^{2}$ \\ ${ }^{1}$ A lecturer of transportation planning and traffic engineering, Faculty of Engineering, Port Said University, 42523, \\ Egypt,Email:mr2.elbany@gmail.com \\ ${ }^{2}$ An associate professor of wireless communications and signal processing of electric engineering, Faculty of Engineering, Port \\ Said University, 42523, Egypt,Email: hebayms@eng.psu.edu.eg
}

\begin{abstract}
Transportation is an important feature that affects the quality of life. Huge increase in population, modernization in all aspects of life, and cities expansion lead to a more congested traffic that may be acceptable for in-emerging trips but enormous for emergency trips, especially for COVID 19 patients with severe respiratory symptoms. Smart transportation techniques offer solutions to the congestion problems for different modes of transportation and traffic management. In this paper, a smart traffic solution to the congestion problem in the major road to isolation hospital in Port Said City is presented.
\end{abstract}

Key words: Smart alarm system, Covid-19 pandemic, ambulance mobility, congestion, isolation hospital, time saving

\section{INTRODUCTION}

Traffic congestion is a pressing problem that has a serious impact on economy, safety, and environment. It is shocking to know that $20 \%$ of patients die on their way to the hospital [1]. So, finding effective solutions to congestion problems has gained great interest in the broader research community [2]. On the practical side, there are many ways to reduce congestion, such as new roads construction, new policies for pricing, changing the transport system from road to train or another effective way smartly.

Smart energy, intelligent transportation, wireless technologies, Global Positioning System GPS, sensing technologies, Internet of Things IoT and Artificial Intelligence AI are smart technologies widely used in smart cities [3]. Wireless communications between vehicles and infrastructures needs innovative real time applications to increase safety and comfort. These real time applications could include commuters to track vehicles with variable messages en-route and to determine low density route in real time also it could be used to study the real time traffic incidents [4].
Variable messages signs can be used on roads to give advice to drivers about traffic conditions or about the best route to follow instead of using congested routes. For private cars, IoT gives maximum benefits coming from better control over related infrastructure and the inherent flaws in vehicle transport. Various techniques such as RFID, Wi-Fi, Bluetooth, and radio communication could be used beside IoT to enhance the traffic systems [5].So, IoT and related control and signal processing systems such as AI are expected to make transportation organizations smarter and more successful at their tasks such as, improving the experience of travelers, reducing incidents and increasing inter/outer-modal safety, reducing congestion and the amount of energy use and giving a more advanced operational performance. In this paper, a smart traffic solution based on AI central control to the congestion problem in the major road to isolation hospital in Port Said City is presented. The paper is organized as follows; major information about Port Said city is presented in section 2. In section 3, COVID 19 pandemic effects are briefly discussed. The proposed smart traffic system is presented in section 4 . In section 5, the traffic data analysis of the proposed system is shown. And finally, the paper is concluded in section 6 .

\section{PORT SAID CITY}

Port Said city is a coastal city located on the Mediterranean Sea in northern Egypt at the entrance of Suez Canal in the north and was named after the khedive Muhammad Sa īd (reined 1854-63), who selected the site of the town. Ferdinand De Lesseps, the engineer who constructed Suez Canal, visited the location of Port Said on the 25th of April 1859 and saw that its location was suitable to be the entrance to Suez Canal, as shown in Fig. 1. By the late 19th century, it was the world's largest coal-bunkering station, catering almost exclusively to the Suez Canal traffic [6].

The harbor is its central point. On the other side of the Canal, there is another town called Port Fouad which considered as one of its administrative area. Between Port Said and Port 
Fouad, there are ferries to cross the Suez-Canal for pedestrians and vehicles. It has experienced rapid growth and used to be a tax-free area that brought a lot of foreign business into the country. The surface area of Port Said is around 1,350 square kilometers with a population that is estimated to be around one million inhabitants at the end of 2020 [7]. The city has seven main neighborhoods with El Arab, Ganoub, El Zohour, Port Fouad, and El Shareq being the most important.

Port Said's traffic network is a Grid network which is common in urban cities. It tends to be centered on the central business district with few routes expressing far away from the central business district (CBD). Its transportation network refers to the framework of roads connected at points which are called nodes. There are roads categorized to arterial, collector, and local road according to its traffic volumes and importance for the commuters. It has two main arterial or main roads; Al-shohada St. and 23 July St. which considered the most important roads that load people from/to the city and connected with highways reach to other cities; Cairo( the capital), Ismailia, Damietta, ...etc. All other roads categorized as collectors and locals are called secondary roads.

There are three ports with many inhabitants work in these ports and the investment area settled to the south of the town access to/from Al-shohada St. as shown in Fig.2. It also attracts students from other countries to its university located at Port-Fouad [8].Al-shohada Street is an entrance two way road with $6.7 \mathrm{~km}$ long and $16 \mathrm{~m}$ width and three lanes in each direction. It is categorized as the most congested route due to its traffic volume which exceeds 30,000 vehicles per day in each direction. This street is considered the main route for emergency cars come to or from Port Said to the neighboring governorates.

All emergency cars transporting COVID 19 patients passed through Al-shohada St. from February 2020 till now. Through it, there are four signalized control intersections causing a delay of at least 6 minutes in travel time in case of free flow which is a summation of red times of traffic signals, deceleration time, and acceleration time. The delay could exceed12 minutes in congestion times [7].

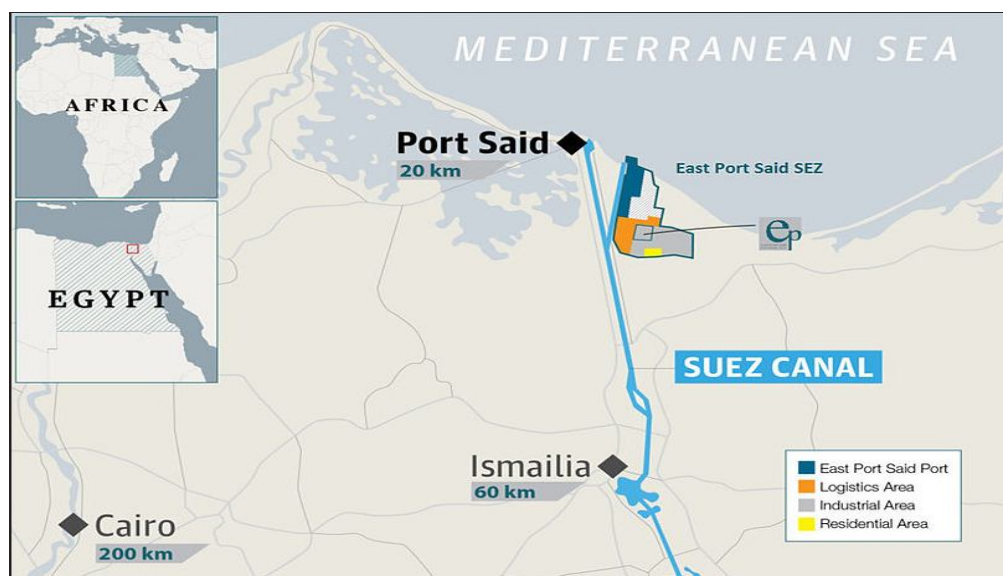

Figure1: Port Said is the entrance of Suez Canal

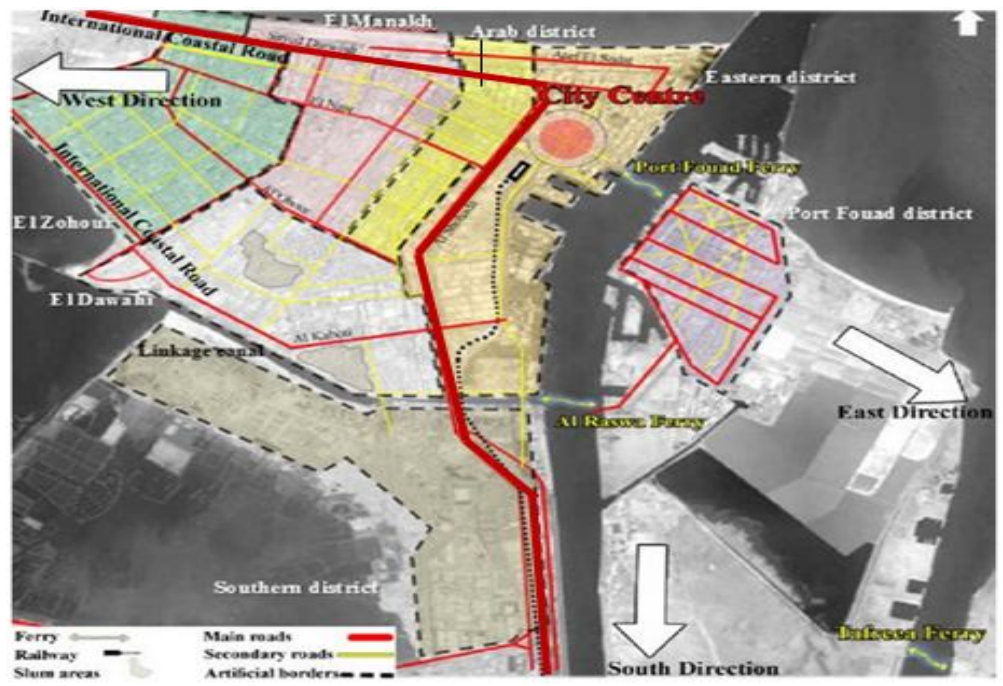

Figure 2: Traffic route of emergency cars towards isolation hospital 


\section{COVID 19 PANEDEMIC IN PORT SAID}

Port Said city is one of the important tourism cities with many ports and all sorts of services and facilities available for the guests of the city. Almost one million [9] of people have been placed under pandemic risk beginning with the end of February 2020 with arrival of many tourism ships. For that reason, the leaders of Port Said Governorate are working on setting the basic main keys to reduce the transfer time of the infected persons to the isolation hospital in Ismailia governorate as one of the solutions to the Covid-19 crisis.

Patients with severe respiratory symptoms couldn't be transferred in family cars. They need to be transferred from hospitals to the isolation hospital as fast as possible in well occupied emergency cars to reduce the probability of death and to increase the efficiency of using the emergency cars available in the city. Once a decision has been made to transport a patient, there is a risk for every minute of delay according to traffic congestion or any un-expected circumstances. In case of Port Said city, Al-Shohada St. is the vital route to/from the treatment trip by the emergency cars spending a travel time inside the city with delay that is classified into two natures; the delay due to congestion and the red-time delay at the signalized intersections. With a crisis like COVID 19, delay is not only a cause of bad impression for people but it is a life/death problem. So, smart transportation systems have to be implemented to reduce delays and effects of traffic congestion at any segment all over the day time.

\section{PROPOSED SMART TRAFFIC SYATEM}

Smart traffic system is where centrally-controlled traffic signals and sensors regulate the flow of traffic through the city in response to traffic volumes [10]. Here, a smart traffic system (as shown in Fig. 3) depending on AI central control is proposed to reduce the delay of the emergency cars through their trips to the isolation hospital outside Port Said city.

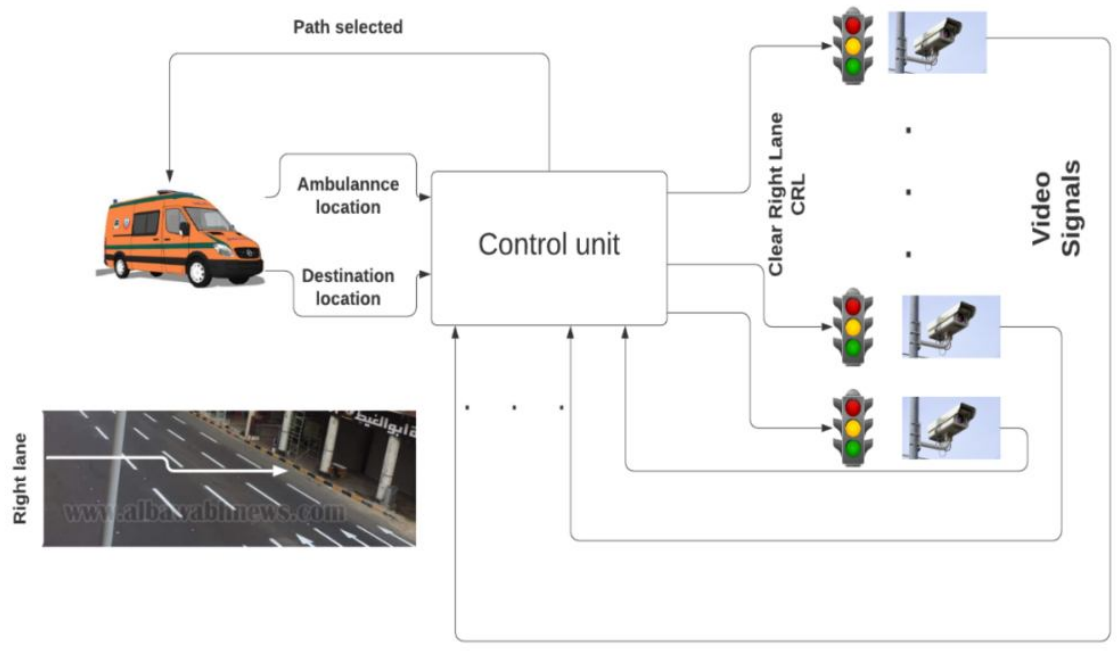

Figure 3: The proposed smart traffic system

After receiving the emergency order, the emergency car communicates with the control unit via exchange of data. Enabled by hardware and software subsystems, the communication process is typically wireless and bidirectional. In emergency cases, the ambulance sends its location ( $\mathrm{x}, \mathrm{y})$ and the destination location $\left(\mathrm{x}_{1}, \mathrm{y}_{1}\right)$ to the control unit. The shortest path with less congestion is chosen accordingly by the control unit and sent back to the ambulance.

Accordingly, all the traffic lights on the chosen path must give a visual signal to car drivers to free the right lane for the emergency car. The control unit sends Clear Right Lane CRL signals to the traffic lights on the decided path. There is no need to exchange the conventional traffic lights with more advanced versions. LED boards could be connected on top of the traffic lights to give a clear vision of CRL to car drivers. To make the process more adaptive, cameras should be also connected to the traffic lights to give the control unit the possibility to track the emergency car and set/reset the CRL signals. The cameras connected to the traffic lights are video cameras to give a continuous tracking for the ambulance through its path. Accordingly, the control unit could stop sending CRL signals to the traffic lights passed by the ambulance. For example, when the ambulance passed the first traffic light and goes toward the second one, the first camera video signal will be processed by the control unit. And, the CRL signal will no longer be sent to the first traffic light through this journey. 
Artificial Intelligence AI is an area of computer science by which machines could function as human brain. AI was first modeled in 1956 by John McCarthy but due to lack of technology, it didn't achieve the expected low levels of error of prediction. Today, with machine learning AI, computers behave as the human brain in dealing with big data to extract required features [11].

Since any amount of data has many uncertainties that cannot be solved with the usually known techniques. AI uses the uncertainties and makes a model for the relationship between causes and effects of different scenarios for much better analysis [12].

AI has many promising applications in transportation and traffic either in autonomous cars or in planning and managing traffic systems. It helps the transportation sector to be safer for passengers, less congested, less polluted with minimal financial costs [13].

Nowadays, transportation systems are an essential part of human life. About $40 \%$ of people all over the world spend at least 60 minutes on roads per day [14].

Intelligent Transportation Systems ITS consists of electronic, communication and control subsystems and sensors for different traffic parameters to improve performance of the transportation process [15].

Continuous monitoring of vehicles and road congestion help utilities to make rapid decisions to traffic problems and emergency cases [15].Vehicle monitoring can be done by static and dynamic cameras. Then, a stage of image or video processing is necessary in the system control unit [16]. The emergency car could be detected by the video camera if a traffic analysis is also required by the control system. The static cameras could also be used with a suitable rate of capturing images [15] and the AI processing stage at the control unit could analyze the images or videos and gives decisions according to the analysis. The mostly suitable type of cameras is the traffic sensor camera. It is typically installed on top of traffic signals or light poles. They are usually enclosed in weatherproof housing to keep sustainability.

The huge amount of data in videos collected by cameras need to be processed continuously in a synchronized rate with the speed of emergency cars. This could be done depending on Artificial Intelligence AI.

AI control unit collects data from all the connected cameras, sensors and other subsystems. Then, it uses machine learning algorithms to process, analyze and gives decisions according to the situation constraints. Accordingly, congestion prevention and delay time reduction are guaranteed in the emergency scenarios.

\section{TRAFFICDATAANALYSISOFTHEPROPOSE D SYSTEM}

Al-Shohada St. is the entrance route that is assigned as an urban - arterial road [17]. It is two way road with $6.7 \mathrm{~km}$ long and $16 \mathrm{~m}$ width with three lanes in each direction beginning from the entrance of the city into the downtown. It is categorized as the most congested route due to its huge traffic volume; more than 30,000 vehicle per day in each direction. This road is considered as the main street route for ambulance cars if it begins trip from nearby areas outside city to any destination in side city or from inside city to the isolation hospital outside city. It has 8 intersections.

Four of the intersections are signalized control intersections and the rest are un-signalized intersections. The average hourly travel time is about 12 minutes in case of free flow speed but in peak hours it exceeds 25 minutes (as shown in Fig.4).The average delay at intersections is about 6 minutes. In case of a pandemic, reducing one minute of delay has a probability of a person survive.

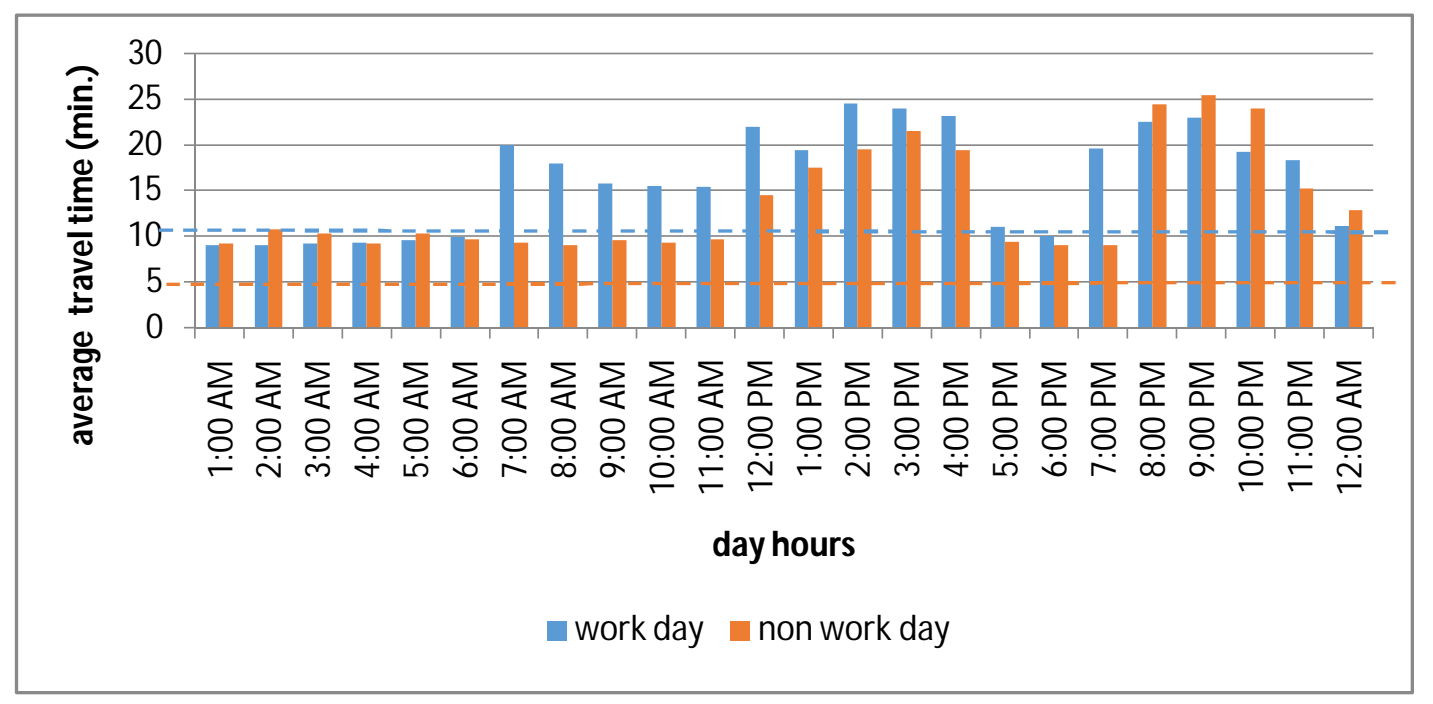

Figure 4:The average travel time fluctuation of Al-Shohada St. during a work day and a non-work day 
Marwa Elbany et al., International Journal of Advanced Trends in Computer Science and Engineering, 10(1), January - February 2021 , 282 - 288

The onsite study of travel time was done manually by four moving cars for each quarter of each hour. Each driver holds a stopwatch to record the travel time then calculating the average value. It was done in Friday as a non-work day. The previous figure shows that there are two travel time peaks in the non-work days; the first peak is almost from 2:00 AM to 4:00 AM and the second peak is from 8:00 PM to 10:00 PM.

In the case of work-day, the study was done in Tuesday, there are three peaks. The first peak is a morning peak from 7:00 AM to 8:00 AM , the second is from 2:00 PM to 4:00 $\mathrm{PM}$, and the third is from 7:00 PM to 9:00 PM.These peaks are considered as danger moments for the emergency transport of patients.
Al-Shohada St. has four sequential traffic lights at intersections. Beside the congestion delay, the control delays at signals are added. The control delay at signals is divided into deceleration, acceleration, and red light period [18]. The average delay is about 1.5 minute at each intersection [7]. It represents a big problem at emergency situations.

According to the proposed smart traffic system STS [19, 20], the delays due to waiting time ( red time, decelerating time, and accelerating time) for each traffic signal were subtracted from a travel time. The expected reduction in travel time is not similar for all day hours. It changes according to the circumstances of travel demand and the weather during the day. In this study, the approximate expected fluctuation of average travel time is shown in Figures 5 and 6.

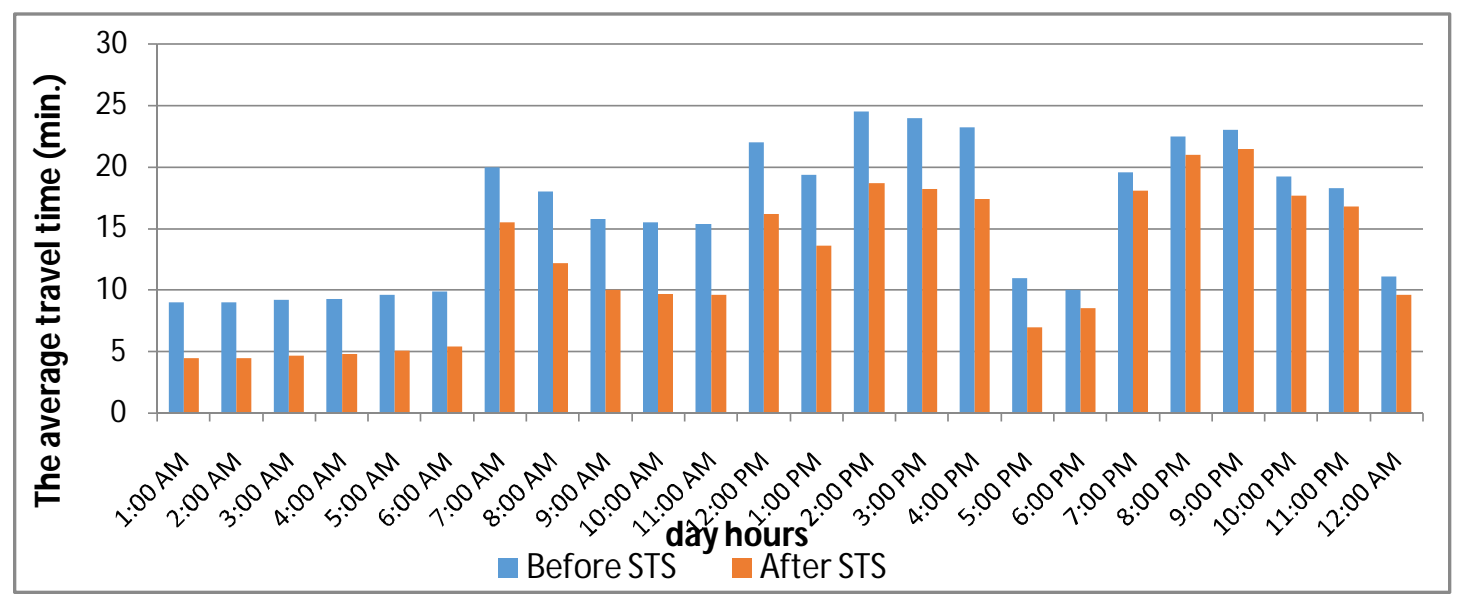

Figure 5: The expected average travel time fluctuation of Al-Shohada St. during a work day before and after STS

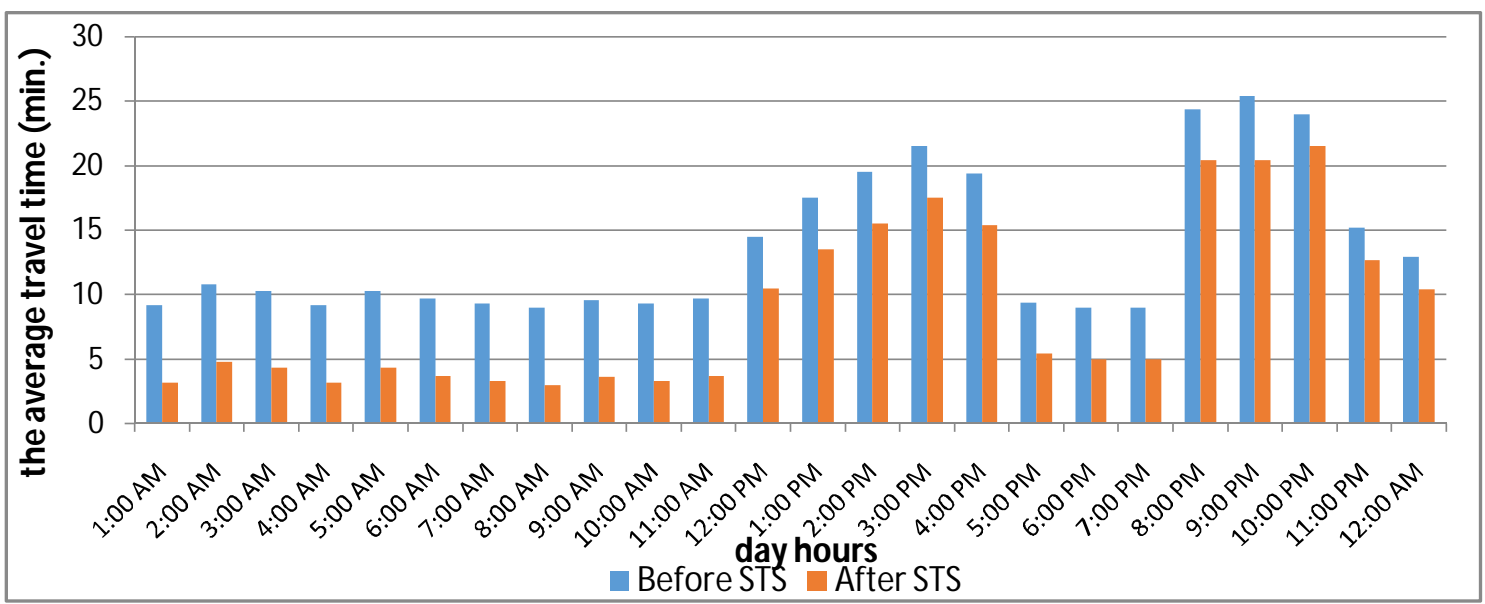

Figure 6: The expected average travel time fluctuation of Al-Shohada St. during non-work day before and after STS

From the previous figures; the saved time of the ambulance car will be about 4.1 and 5 minutes in workdays and nonwork days; respectively that proves that STS can help in saving life during worse crisis such as pandemic by reducing delay times of ambulance and rabidly transform of traffic data.

\section{CONCLUSION}

Covid-19, the current virus pandemic, forces the intercity traffic planners to transform inner-city transportation in line with smarter technologies including traffic control and information technologies. Such technologies could possibly offer an once-in-a-lifetime opportunity by reducing congestion and control movement of people. This paper introduces a proposed smart transportation system in order to 
reduce delays and effects of traffic congestion of ambulance cars. It extends to present innovations that enable the transport system to improve its performance.

The case study is Al-Shohada St. in Port Said city which considers the main arterial road to enter the city and to every emergency car that needs to reach a hospital. It contains four signalized intersections. The study proposed a smart alarm traffic management system is where centrally-controlled traffic signals and sensors regulate the flow of traffic through the city in response to traffic volumes. It depends on Artificial Intelligent AI central control that handles traffic data with aggregated and dispersed data, and handles a larger amount of information collected from various sources. The proposed system consists of electronic, communication and control subsystems and sensors in order to collect and transform data efficiently.

Traffic data of the selected road had been collected in workdays and non-work days. The average delay is about 1.5 minute at each intersection that represents a big problem at emergency situations. After applying the proposed system, the saved time of the ambulance car is expected to be 4.1 and 5 minutes in workdays and non-work days which proved the effectiveness of using such systems. This study gives an idea about how to deal with crisis using new communication systems applied on congested transportation systems. The future research will be in how to connect the local transportation with other urban networks together to transform data and construct an application to be easy in use.

\section{REFERENCES}

1. M. Godoy .How COVID-19 Kills: The New Coronavirus Disease Can Take A Deadly Turn. An article published 14-Febreuary, 2020.

https://www.npr.org/sections/goatsandsoda/2020/02 /14/805289669/how-covid-19-kills-the-newcoronavirus-disease-can-take-a-deadly-turn

2. European Commission. Intelligent transport systems, innovating for the transport of the future.Europe: European commission Retrieved 2017

fromhttps://ec.europa.eu/transport/themes/its_en

3. M. Liu, D. Yang, and F. Hao. Research Article: Optimization for the Locations of Ambulances under Two-Stage Life Rescue in the Emergency Medical Service: A Case Study in Shanghai, China, 2017.

4. M. Unterkoer and R. Schmiedel. Verbesserung der sicherheitbeisondersignaleinsatzen. Bergischgladbach, info 34/95. WissenschaftlicheInformationen der BundesanstaltfurStra_enwesen, 1995.

5. L. Garcia, J. Jimenez, M. Taha and J. Lloret.Wireless Technologies for IoT in Smart
Cities. Network Protocols and Algorithms Jounal. ISSN 1943-3581, Vol. 10, No. 1, 2018, pp.8-17.

6. Z. Aklikim, K. Berger, A. Ibrahim, P. Bah, F. Luvas and A. Schraub. HAL technical report. Creation of a transport system in Port Said, Egypt: What kind of transport for a developing country?,Journal of transport studies, 2018.

7. M.Shahin, IB. Hashim,M. S. Serag, and M. ElBany. Policy Sensitive Mode Choice Analysis of Port-Said City, Egypt. Alexandria Engineering Research Journal, Faculty of Engineering, vol.14, 2014, PP..3.

8. Port Said university website:http://www.psu.edu.eg/

9. World Health Organization (WHO).Timeline statement with title "Timeline of WHO's response to COVID-19".Last updated 30 July 2020.

https://www.who.int/news-room/detail/29-06-2020covidtimeline

10. M. Agila , P. Karthikeyan and A. Kumar. Smart Traffic System for Ambulance Using RFID and Internet of Things. $3^{\text {rd }}$ National Conference on Innovative Research Trends in Computer Science and Technology (NCIRCST 2018). ISSN: 24544248. Volume: 4. Issue: 3, 2018, pp. $121-125$.

11. R. Abduljabar, H.Dia, S. Liyanage and S. Asadi.Applications of artificial intelligence in transport: An overview. Sustainability 2019, Vol.11,pp.189.

12. Z. Ullah, F. Al-Turjman, L. Mostarda and R. Gagliardi.Applications of artificial intelligence and machine learning in smart cities. Elsevier, Computer Communications, March 2020.

13. A. Games, P. Cortez, J. Tinoco, and R. Marques, Artificial intelligence applications in transportation geotechnics.Geotech. Geol. Eng., 2013, Vol. 31pp.861-879.

14. J. Zhang, F. Wang. Data driven intelligent transportation systems: A survey. IEEE transactions on intelligent transportation systems, Vol. 12, No. 4, Dec. 2011.

15. P. Tasgaonkar, R. Garg and P. Kumar. Vehicle detection and traffic estimation with sensors technologies for intelligent transportation systems. Sensing and Imaging, June 2020.

16. J. Zhou, D. Gao and D. Zhang.Moving vehicle detection for automatic traffic monitoring. IEEE Transactions on vehicular technology, Vol. 56, No.1, Jan. 2007.

17. Y. Tang and A. Ismail. Highway \& Traffic Engineering Road Classification and Design Standard in Malaysia. A presentation of Faculty of Civil Engineering \& Earth Resources, Universiti Malaysia Pahang, 2019.

https://www.academia.edu/36824766/Highway_and _Traffic_Engineering_Road_Classification_and_De sign_Standard_in_Malaysia 
18. T. Abdel-Wahed.Measuring Control Delay at Signalized Intersections: Case Study from Sohag, Egypt.International Journal of Advance Research of Science and Engineering, Vol.No.5, 2018.

19. L. Sumi andV. Ranga.Intelligent Traffic Management System for Prioritizing Emergency
Vehicles in a Smart City.International Journal of Engineering, Transactions B: Applications 31(2), 2018,pp.278-283.

20. H. Mewada.Review on Smart Traffic Control for Emergency Vehicles,2015, 112(7). 